http://economix.fr

\title{
The Risk Parity Principle applied on a Corporate Bond Index using Duration TimeTSpread
}

\section{Document de Travail}

Working Paper

2016-27

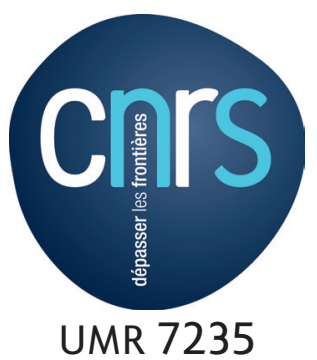

UMR 7235
Université de Paris Ouest Nanterre La Défense (bâtiment G)

200, Avenue de la République 92001 NANTERRE CEDEX université

Paris Ouest

Nanterre La Défense 


\title{
The Risk Parity Principle applied on a Corporate Bond Index using Duration Times Spread
}

\author{
Lauren Stagnol*
}

September 9, 2016

\begin{abstract}
In this paper, we apply the principle of Equal Risk Contribution (ERC) to a corporate bond index, an asset class so far left behind in this literature. Specifically, we rely on the Duration Times Spread (DTS) and demonstrate that it is a coherent metric for bond risk. We construct indexes based on sector - issuer - and bond level using structured block correlation matrices, weights being inversely proportional to DTS. Our results provide evidence that applying ERC using DTS in the index design significantly improves corporate bond index risk-adjusted returns. It appears that the higher the granularity is, the higher will be the riskadjusted performance enhancements. More generally, the ERC application we present seems to be a valuable trade-off between heuristic and more complex risk-modeling based weighting schemes.
\end{abstract}

JEL Classification: G10, G11, C60

Keywords: Equal Risk Contribution, Risk Parity, Smart Beta, Risk Measure, Risk-Based Indexing, Alternative Corporate Bond Index

\section{Introduction}

Since the inception of the Dow Jones Industrial Average created by Charles H.Dow in 1896, indexing has attracted hundreds of billions of dollars. By averaging stock prices of twelve companies, he was the first to offer the opportunity to gauge market performances. Then it just took a small step from appraising general market moves to tracking it. This is when the concept of benchmark came along. A benchmark reflects the market's mood, and an index aims at

*EconomiX-CNRS, University of Paris Ouest Nanterre La Défense, 200 avenue de la République, 92000 Nanterre, France and Amundi Asset Management, 91 boulevard Pasteur, 75015 Paris, France. Email: l.stagnol@gmail.com. The views expressed in this paper are those of the author and do not necessarily reflect those of Amundi.

I am very grateful to Marielle de Jong, Valérie Mignon, Christophe Boucher and Sessi Tokpavi for their helpful comments and suggestions. 
mimicking it. In this sense indexing allows an investor to hold the market. Subsequently to Charles H.Dows simple average of stock values, the financial industry came up with more refined weighting schemes. More precisely, indexes are now generally capitalization weighted: the higher the capitalization of an entity, the larger its weight in the index. The rationale behind such practice emanates from the Capital Asset Pricing Model (CAPM) introduced by Sharpe (1964), pillar of modern finance theory. Under a set of theoretical assumptions, it is argued that the market portfolio is the most efficient in a risk/return framework. Therefore, according to the CAPM, investors should hold the market which implies investing in an asset proportionally to its market share: that is the market capitalization. Even though fierce debate remains concerning the validity of the assumptions behind this founding model (and especially the Efficient Market Hypothesis), capitalization weighting has been the norm in the equity space for decades now. This applies to bonds as well.

However, cap-weighting may present some flaws (Haugen and Baker, 1991; Hsu, 2006). To illustrate, by construction such approach tends to exacerbate price variations and assets weights will mechanically be proportional to this distortion, which can reveal to be hazardous in case of irrational price moves and subsequent market correction. Indeed, price dependency prevails since capitalization is simply the product of price per share times the number of outstanding shares. As far as fixed income products are concerned, the capitalization of an issuer is the amount of debt he issues on the market. The implication is not trivial: cap-weighted bond indexes have a heightened exposure to the most indebted issuers. We have seen the trauma it can cause, as provoked by the overweight of Greek debt at the dawn of the European sovereign debt crisis. Corporate bonds are not better off than their sovereign counterparts, as they are neither immunized against heavily weighted entities being downgraded and thus exiting the investable universe, nor against harsh default.

More generally, flaws from capitalization-weighting led to the emergence of alternative weighting schemes. From heuristic approaches to more sophisticated schemes, both academics and practitioners contributed to make alternative indexing a very hot topic for the fixed income market. These novel ways of indexing can be classified into two broad philosophies: fundamentals-based versus risk-based approaches. On the one hand, fundamental indexing refers to weighting schemes that rely on economic metrics. From balance-sheet data (for both corporate bond and equity worlds) to national accounts (for sovereign bonds): it is all about appraising the economic footprint of an index's constituent. Examples include company's solvability, GDP or size weighting schemes for the bond and equity universes respectively (Arnott et al., 2005; de Jong and $\mathrm{Wu}$, 2014; de Jong and Stagnol, 2016). On the other hand, risk-based indexing is more concerned with risk diversification and led to the development of a few ad-hoc approaches, such as Equally Weighted indexing (EW hereafter) as well as more complex designs (Minimum Variance, Most Diversified, Maximum Diversification for the equity world) to name a few, that rely on risk modeling 
(Amenc et al., 2011; Cazalet et al., 2013). Risk parity belongs to that second category, in the sense that it sets weights in order to equalize risk budgets across assets. From that standpoint, Equal Risk Contribution (ERC hereafter) can be considered as a special case of risk parity where each asset's risk contribution is made equal in a portfolio. Adopted in the equity world since a few years now, interest for sovereign bonds has risen recently (Bruder et al., 2012). However corporate bonds are still generally left aside. Filling this gap, this paper presents the application of an ERC indexing scheme to a global corporate bond index. ${ }^{1}$

In doing so, we contribute to the literature in several ways. First, we propose a new elementary risk measure, namely the Duration Times Spread (DTS hereafter) that does not require any modeling or calibration issues. Moreover, this is the first time to our knowledge that DTS is presented as a coherent risk measure in a formal framework. Second, using structured block correlation matrices, we demonstrate that the use of this parsimonious measure in a risk parity scheme allows substantial improvement in the risk-return space. Third and more generally, our results allow enlarging the scope of assets classes for which it is pertinent to apply ERC principle to corporate bonds.

Section 2 briefly reviews the literature on that topic, and motivates the use of DTS as a measure of bond risk. In section 3 we verify that the latter can be considered as a coherent risk measure in a more formal framework and provide empirical grounds for its use as a risk metric. Section 4 presents the analytical solutions to implement an ERC weighting scheme as well as the methodology employed, while section 5 provides back-tests of these alternatively weighted benchmarks. Section 6 is devoted to performance's analysis. Finally, section 7 concludes the paper.

\section{Literature review}

Maillard et al. (2010) recall that the ERC strategy is directly derived from the risk budgeting techniques developed by Scherer (2007) and that in that sense the ERC approach is the simplest risk budgeting rule. Building on risk budgets when optimizing asset allocation should reduce the overall portfolio risk. Risk parity portfolios, and more precisely ERC strategies exist on the market since a couple of decades now (for instance the All Weather fund, a multi asset class risk parity fund from Bridgewater dates back to 1996). However at the aftermath of the financial crisis, a revival of interest in such strategies has arisen, driven by investors forced to reconsider their traditional asset allocation. While the definition of risk is generally consensual for equity - volatility, (Bruder and Roncalli, 2012; de Carvalho et al., 2012) the same cannot be argued on the fixed income side. Indeed, bonds incorporate risk from various dimensions that can

\footnotetext{
${ }^{1}$ The aim of this paper is not to appraise potential currency effects, thus here we make the underlying assumption that the index is currency-hedged.
} 
be summed up under two main drivers: default and interest rate risks. Optimizing a portfolio such that each asset has the same risk contribution to the overall risk implies that risk is defined. So far, only a few papers focused on the fixed income world (Bruder et al., 2012; Bruder and Roncalli, 2012) and we believe that the choice of the risk definition can be held responsible for that. Indeed, in most cases of ERC applications, bonds are considered as a simple "bucket", and opposed to equity in the optimization process of a mixed portfolio, that is finding the weight such that the bond and the equity buckets bring about the same contribution to the global portfolio (Bruder and Roncalli, 2012; Chaves et al., 2011; Qian, 2005). In such exercise, bond risk is simply apprehended through volatility. As argued by Roncalli (2013), (price) volatility tends to reflect interest rates yield curves fluctuations rather than issuer specific characteristics. Some authors then considered the peculiarities of fixed income instruments and subsequently incorporate their intrinsic risk dimensions. For instance, Bruder et al. (2012) design a sovereign bond portfolio where they choose to equalize the credit risk component estimated through the analysis of a Credit Default Swap (CDS) spreads basket across countries. Switching from price volatility to credit risk approximation is a big step towards the development of fixed-income adequate ERC strategies. Still, as explained before, bonds are complex instruments subject to several risks: it is often argued that the main risk drivers for bonds are the credit and interest rate risks (Roncalli, 2013). In their paper Bruder et al. (2012) developed a measure of the credit risk component (the product of bond duration, CDS spreads volatility and level) that they estimate through a Stochastic Alpha Beta Rho (SABR) model, a stochastic volatility model (Hagan et al., 2002). Combined with the allocation of risk budgets to countries accordingly to their economic scale, ERC using their credit risk measure shows promising results, performance being enhanced for a given level of volatility.

In this paper, we depart from the previous literature in two main points: the use the DTS as a measure of risk and the assumption on the correlations structure. As far as the use of DTS is concerned, we believe that duration allows to efficiently capture interest rate risk while the credit spread translates default risk. Concerning the spread, it is generally recognized that it allows capturing credit risk and in that sense, reflects a default premium (Longstaff and Schwartz, 1995; Gatfaoui, 2008). As opposed to Bruder et al. (2012) paper, we use credit spreads provided by a data vendor instead of CDS spreads data. Here when we refer to spread, we imply the Option Adjusted Spread, expressed in basis points, calculated over the fair value government spot rate curve. We argue that this approach is more instinctive, considering that we work on a universe of given assets (with their specific characteristics) for which credit spreads are directly available, (our analysis only relies on Merrill Lynch market data) and thus there is no need to use CDS spread to approximate an issuer credit risk. Additionally, we work on a rather low frequency - monthly - dataset, dismissing issues of data deficiency. Moreover, even though it is sometimes argued that CDS are generally more liquid, in the end both spreads convey the same information concerning default (Blanco et al., 2005; Zhu, 1964). Finally, the "zero 
difference" CDS-bond basis ${ }^{2}$ might not hold during our sample period in the sense that it may also capture funding, collateral and counterparty risks during troublesome market conditions, thus discouraging the use of CDS spread in our credit risk estimation (Bai and Collin-Dufresne, 2013). As far as duration is concerned, it reflects the sensitivity of a bond to shifts in the interest rate. This permits taking into account price fluctuations resulting from a variation in the interest rate, which is a primary risk in the fixed income world, and particularly if the bond is not hold until maturity. The higher the duration, the stronger will be the reaction following a change in market conditions. A founding paper written by Ben Dor et al. (2007) introduces the conjunctive use of these two measures, named the DTS. The authors advocate for approximating systematic change's exposure in spread by its contribution to DTS. This way, using the Effective Duration and the Option Adjusted Spread (vs Govt) in our risk parity principle application allows to take into account the main risk drivers at plays in the fixed income world.

As far as our method specificity is concerned, we depart from the current literature in the sense that we structure block correlations so that we have equal off-diagonal block elements as in Disatnik and Katz (2012). Blocks will be constructed in accordance with the intended parity strategy. We consider three different block levels: sector, issuer and bond, the latter being mainly theoretical. Indeed at that level, results depend from the number of bonds issued and thus may lead to unfounded overweighting of some companies or sectors. To illustrate, a company can choose to issue $\$ 1$ million debt in one single bond issuance or multiple: the latter would artificially result in overweighting that firm in the index proportionally to its number of credit lines. From a theoretical point of view, assuming equal correlation within issuers from a given sector and no correlation between the sectors, although of course over-simplifying, remains reasonable. In addition, artificially shrinking the variance covariance matrix in that manner allows to considerably reduce the optimization problem, while breaking the link with variance covariance estimation, thus decreasing potential data or estimation related bias.

\section{DTS as a coherent risk measure}

As recalled by Bruder et al. (2012), in order to implement the ERC weighting scheme it is necessary to employ a coherent and convex risk measure. Here, we aim at demonstrating that DTS satisfies those criteria. Coherence has a particular meaning in the financial risk modeling and to be considered as a coherent risk measure, a risk function has to satisfy four mathematical properties

\footnotetext{
${ }^{2}$ This is the difference between the CDS spread and the bond spread for a given company, and is presumed to be slightly positive, notably due to the "cheapest to deliver option" effect intrinsic to CDS and the potential difficulty to short-sale corporate bonds (Bai and CollinDufresne, 2013).
} 
(Artzner et al., 1999): monotonicity, sub-additivity, positive homogeneity and translation invariance. We make the hypothesis that the bond correlation matrix has equal off-diagonal elements. ${ }^{3}$ To obtain the DTS formula, let us write the Macaulay duration equation (Bodie et al., 2004), adjusted by the coupon frequency $\mathrm{k}$.

$$
\text { Macaulay duration }=\frac{\frac{(1+y / k)}{y / k}-\frac{((1+y / k)+T(c / k-100 y / k))}{\left((c / k)\left[(1+y / k)^{T}-1\right]+100 y / k\right)}}{k}
$$

where $y=$ Yield (per year, in decimal form),

$c=$ Annual coupon $\%$,

$T=$ Number of coupon periods.

As far as the spread component is concerned, we simply define it as:

$$
\text { Spread }=y-y_{\text {gov }}
$$

where $y_{\text {gov }}=$ the yield of a government security with identical properties (maturity, currency). Combining the duration and the spread component, we obtain the following formula for DTS:

$$
D T S=\left[\frac{\frac{(1+y / k)}{y / k}-\frac{((1+y / k)+T(c / k-100 y / k))}{\left((c / k)\left[(1+y / k)^{T}-1\right]+100 y / k\right)}}{k}\right]\left(y-y_{\text {gov }}\right)
$$

Assuming coupon, number of coupon periods, coupon frequency and risk-free rate held constant for two bonds $\mathrm{A}$ and $\mathrm{B}$ with $y_{A}<y_{B}, Y$ being a portfolio, $\alpha$ and $n$ are constants and $\delta \in[0,1]$, we can now verify the following axioms:

1. Monotonicity

$$
\operatorname{DTS}(A)<D T S(B)
$$

2. Sub-additivity

$$
\operatorname{DTS}(A+B) \leq D T S(A)+\operatorname{DTS}(B)
$$

3. Positive homogeneity

$$
\operatorname{DTS}(n Y)=n \operatorname{DT} S(Y)
$$

where $n \geq 0$

4. Translation invariance

$$
D T S(Y+\alpha)=D T S(Y)+\alpha
$$

\footnotetext{
${ }^{3}$ More specifically, equal off-diagonal elements only apply to "bond" and "full parity" indexes. Indeed, for other indexes presented in this paper, we have equal off-diagonal block elements as in Disatnik and Katz (2012). To illustrate, in the sector parity framework, we assume no correlation between the sectors, but equal correlation within a given sector. More generally, we have null between-block correlation with equal within-block correlations.
} 
We can relax the positive homogeneity as well as the sub-additivity criteria if they are replaced by the convexity axiom, namely:

$$
D T S(\delta A+(1-\delta) B) \leq \delta D T S(A)+(1-\delta) D T S(B)
$$

It is worth mentioning that it is generally assumed that the DTS of a portfolio is simply the weighted average of its asset's DTS. Here, we concede to this hypothesis, still the rationale behind such aggregation could be questioned. ${ }^{4}$ The sub-additivity constraint refers to the potential diversification benefits from pooling risk while the axiom of positive homogeneity connotes that increasing the size of the portfolio by a factor $n \geq 0$ should proportionally raise its overall risk. Translation invariance can be interpreted as the unchanged level of portfolio risk if cash (or a risk-free asset) is added.

In order to verify the convexity axiom, and to ease deriving analytical solutions, we generate two vectors, $y_{A}$ and $y_{B}$, of 10'000 random values drawn from a log normal distribution with a mean of 1 and a standard deviation of 0.5. T, $c, k$ and $y_{\text {gov }}$ being exogenous, we set the values of $20,10,1$ and 0.5 respectively. In a first round of simulations, we compute $D T S_{A}$ and $D T S_{B}$, according to the formula presented before, multiplied by the yield to account for proportionality, as in as in Ben Dor et al. (2007). Figure 1 allows to verify that DTS effectively complies with the monotonicity axiom. We are thus left with two vectors of $10^{\prime} 000$ observations. Then generating $\delta$, a random variable that ranges from 0 to 1 we compute both the left and right hand sides of the convexity equation (8), that we respectively call Term 1 and Term 2. Results are represented below in Figure 2.

We observe that the DTS effectively complies with the convexity prerequisite since Term 1 is always lower or equal to Term 2. Consequently, we argue that this coherent risk measure is suitable to use in the risk parity framework, and so in an index design process. Now that we have provided theoretical arguments backing the use of the DTS as a pertinent risk measure of a bond, we are keen to turn towards empirical evidence. We want to assess empirically if DTS and a more conventional risk measure, such as estimated volatility of excess returns, are effectively correlated. Excess returns are securities returns that exceed their benchmark, so in the case of corporate bonds, they are compared to a duration-matched government bond or swap. We work on a global corporate bond index, namely the Global Large Cap Index (G0LC), from Merrill Lynch for

\footnotetext{
${ }^{4}$ As an illustration, computing the Diversification Ratio (DR), defined by Choueifaty and Coignard (2008), of a portfolio $p$ on DTS, $w_{i}$ being the weight of asset $i$, and $\sigma_{i}$ the risk associated to the asset $i$, we would obtain:$$
D R(p)=\frac{\sum_{i=1}^{N} w_{i} \sigma_{i}}{\sigma_{p}}=\frac{\sum_{i=1}^{N} w_{i} D T S_{i}}{D T S_{p}}=1
$$

Which is clearly a degenerated case that results from the fact that a portfolio DTS is calculated from an aggregation of asset's risk measure while volatility is directly estimated from the overall portfolio.
} 
Figure 1: Monotonicity

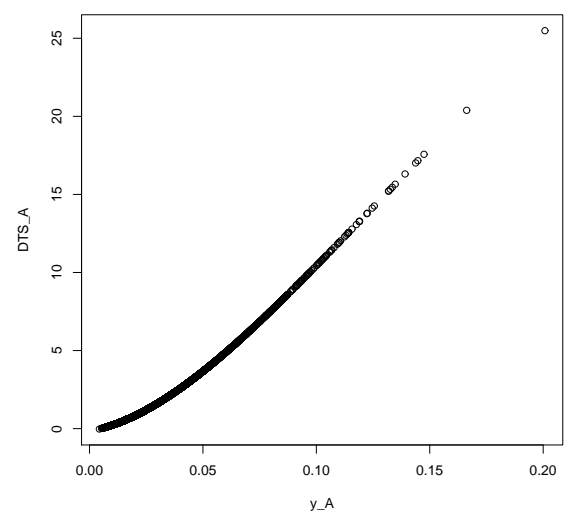

Figure 2: Convexity

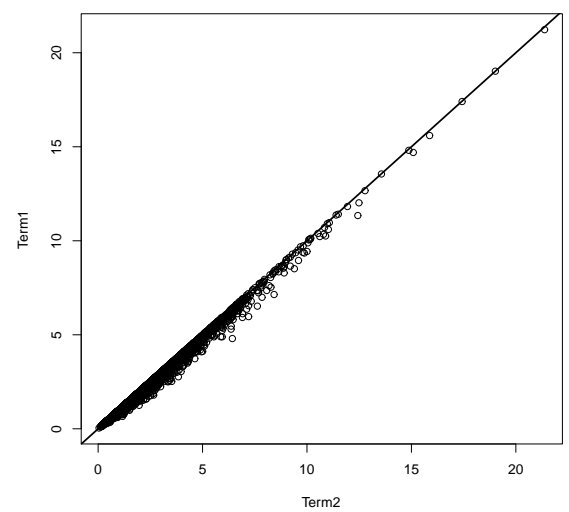

which we have constituents from $12 / 31 / 1996$, its inception date, to $12 / 31 / 2015$ comprising of 18213 distinct bonds from 2424 different issuers over the period. ${ }^{5}$ For each issuer we measure excess returns volatility of its securities issuances as well as average DTS over a 36-month trailing time-window as in Ben Dor et al. (2007). Hence, excess return's volatility is simply the variance of excess returns over the last three years. Therefore, we discard issuers that remain for less than three years in the index, still we manage to construct an unbalanced panel data of $\mathrm{N}=1482$ and $\mathrm{T}=193$, that is 88599 time $\mathrm{x}$ date observations.

As a first step, we test the unit root hypothesis in the volatility of excess returns and the DTS using Levin, Lin and Chu (2002) and Im, Pesaran and Shin (2003) nonstationarity tests. The latter as well as Augmented Dickey Fuller and Phillips-Perron tests allow for individual unit root processes.

Table 1: Panel Unit Root Tests

\begin{tabular}{|c|c|c|}
\hline & Vol excess returns & $D T S$ \\
\hline Levin, Lin \& Chu t* & $-69.81^{* * *}$ & $-45.28^{* * *}$ \\
\hline Im, Pesaran \& Shin W-Stat & $-19.32^{* * *}$ & $-7.04^{* * *}$ \\
\hline ADF- Fisher Chi-square & $4557.46^{* * *}$ & $4753.82^{* * *}$ \\
\hline PP Fisher Chi-square & $4009.17^{* * *}$ & $4162.65^{* * *}$ \\
\hline
\end{tabular}

Notes: SIC criterion and Newey West procedure were used to determine optimal lag length

\footnotetext{
${ }^{5}$ We focus on positive DTS and only keep corporate bonds, eliminating covered and agencies securities.
} 
Results are presented in Table 1 and show that the unit root null hypothesis is rejected for both series. In the aim of assessing whether volatility (Vol excess returns) and DTS are proportional, i.e whether they capture the same underlying phenomenon, we estimate the following baseline model:

$$
\text { Vol excess returns } s_{i t}=c+\beta D T S_{i t}+\epsilon_{i t}
$$

where $\epsilon_{i t} \sim N\left(0, \sigma^{2}\right)$ is the $i . i . d$ error term.

We test different specifications: a pooled version, a one way cross-section fixed effects model (adding $\alpha_{i}$ in the right hand side of the above equation), a one way period fixed effects model (that is $\delta_{t}$ ) as well as a two ways specification (simultaneously adding $\delta_{t}$ and $\alpha_{i}$ ). While the former assumes homogeneity across observations, we wonder how plausible is that hypothesis on the corporate bond market, and therefore also test specifications with cross-section fixed effects as well as period fixed effects. In addition, for robustness matters, we substitute cross-section fixed effects with macro-industry dummies in order to tackle heterogeneity across economic sectors, a stylized fact well documented (Longstaff and Schwartz, 1995; Barnhill Jr and Maxwell, 2002). Results presented in Table 2 show that the DTS and the volatility of excess returns do present a positive relationship. Such observation is robust across specifications.

Table 2: Panel OLS results 12/31/1999-12/31/2015

\begin{tabular}{|c|c|c|c|c|c|c|}
\hline & Vol excess returns & Vol excess returns & Vol excess returns & Vol excess returns & Vol excess returns & Vol excess returns \\
\hline $\mathrm{C}$ & $-4.2273^{* * * *}$ & $-8.8110^{* * * *}$ & $-3.7838^{* * * *}$ & $-9.0225^{* *}$ & $-5.7260^{* * * *}$ & $-5.2895 * * *$ \\
\hline DTS & $0.0096^{* * * *}$ & $0.0146^{* * * *}$ & $0.0091^{* * *}$ & $0.01478^{* * *}$ & $0.0097^{* * *}$ & $0.0092^{* * *}$ \\
\hline Dummy Consumer & & & & $0.2581^{*}$ & $0.2834^{* *}$ & \\
\hline Dummy Financials & & & & $4.2025^{* * *}$ & $4.1505^{* * * *}$ & \\
\hline Dummy Utilities & & & & $-0.7434^{* * * *}$ & $-0.6062^{* * * *}$ & \\
\hline Cross section fixed effects & NO & YES & NO & YES & NO & NO \\
\hline Periods fixed effects & NO & NO & YES & YES & NO & YES \\
\hline F stat & $19711.14^{* * *}$ & $105.1562 * * *$ & $139.0929^{* * * *}$ & $103.4732 * * *$ & $5592.942 * * *$ & $151.5869^{* * *}$ \\
\hline $\mathrm{R}^{2}$ & 0.1810 & 0.6414 & 0.2329 & 0.6659 & 0.2016 & 0.2516 \\
\hline Schwarz criterion & 8.0534 & 7.4193 & 8.0140 & 7.3735 & 8.0298 & 7.9899 \\
\hline
\end{tabular}

This preliminary analysis confirms that it makes sense to approximate a bond risk by its DTS, if we want to implement an analogue strategy to what is done on the equity side. In that sense, our results echoe those of Ben Dor et al. (2007) who found a positive relationship between DTS and excess return volatility. Therefore, we argue that DTS is a suitable approximation of bond risk, and that consequently it is coherent to use this parsimonious measure in a risk-parity framework. 


\section{Analytical derivations and methodology}

Now that we have presented evidences in favor of the appropriateness of DTS as a risk measure for corporate bonds, we construct an index using the latter. More precisely, weights are defined as an inverse function of risk. Under the hypothesis that the correlation matrix has equal off-diagonal elements within block $^{6}$, an asset weight $w_{i}$ can thus be approximated by inverting its marginal risk contribution $\sigma_{i}$ :

$$
w_{i} \sim \frac{1}{\sigma_{i}}
$$

We construct six indexes based on the ERC principle, on different levels, in addition to the Capitalization-Weighted (CW hereafter) benchmark and the EW indexes that are presented for comparative purposes. Below in Table 3 we sum up the different ERC weighting schemes, while the detailed analytics are developed in Appendix A. We recall that these weighting schemes are guided by the assumptions we make on the correlation structure, the "block" level we work on (bond, issuer or sector).

Table 3: Weighting schemes definition

\begin{tabular}{lccc}
\hline Index & Sector level & Issuer level & Bond level \\
\hline CW benchmark & & & CW \\
Equally Weighted & & & EW \\
Bond parity & & & ERC \\
Issuer parity & & ERC & CW \\
Issuer parity within & & ERC & ERC \\
Sector & ERC & CW & CW \\
Sector parity within & ERC & ERC & CW \\
Full parity & ERC & ERC & ERC \\
\hline
\end{tabular}

Notes: The table reads as follow: the "issuer parity within" index weights issuers inversely proportional to their risk, and then within an issuer, securities are again weighted inversely proportional to their risk. On the contrary, the "issuer parity" index only weights issuers inversely proportional to their risk, securities then being cap-weighted within an issuer.

More precisely, we design six indexes on the basis of the risk parity principle. The first one, and perhaps the strictest, is the bond parity index. We set weights such that each bond has the same risk contribution to the overall index DTS, thus allowing companies with multiple bond issuances to reach a high

\footnotetext{
${ }^{6}$ Such assumption can be used in portfolio optimization context, thus working as a shrinkage estimator (Kim et al., 2014; Raudys, 2013). We employ the block methodology, as in Disatnik and Katz (2012) which implies that the covariance matrix is built on block levels, variances are computed on the sample, so are within-block covariances. The between-block covariance is assumed to be null.
} 
weight. Consequently the bond parity index is presented here mainly for theoretical purposes, the rationale behind being potentially questionable. In contrast, the issuer parity index focuses on equalizing the risk contribution across companies. The issuer parity and within index combines the two approaches presented above, ensuring that all companies have the same contribution to risk, while bond's risk contributions within a given issuer are also equalized. Sector parity indexing consists in giving the same risk exposure to all industrial sectors in terms of DTS. Adding a constraint of equal risk contribution across companies within each sector to the latter produces the "sector parity within" index, perhaps the most sensible strategy in practice, which is akin to the "two-step approach" found in the equity universe (Russo, 2016). Finally, to expand the theoretical exercise, we go a layer deeper by designing a "full parity" index, where each sector brings about the same risk contribution to the overall index, ensuring that each issuer risk contribution within a given sector is equalized, while each bond issued by a given company bring about the same amount of risk to the overall issuer DTS.

We still work on the G0LC, a global investment grade corporate bond index that constitutes our benchmark. The index inception date goes back to 12/31/1996, with monthly market data being provided by Merrill Lynch on a monthly basis up to $12 / 31 / 2015$ with "as of" constituents to avoid survivorship bias. For each security, we employ Total Rate of Returns, Effective Duration and Government Option-Adjusted Spread (Govt OAS hereafter). Effective duration reflects the percentage variation in a bond's price resulting from a parallel shift in the semi-annual coupon government yield curve, while controlling for constant option-adjusted-spread. The Govt OAS is computed on the basis of the bond's underlying currency-matched government yield curve and is expressed in basis points. We keep the biggest countries in terms of amount of bonds issued, leading us to retain 42 countries which account for $98.42 \%$ of the benchmark index (see Appendix B for details).

Setting the weights inversely proportional to the DTS will inflate bonds whose DTS tends towards 0 , which is disruptive. In order to avoid such pitfalls, we first decide to restrict ourselves to holding bonds whose duration has never fallen below 0 . We note that this often occurs for callables for which the call date is coming up (Xie et al., 2009). More specifically this implies that when a bond's duration falls below 0, it then exits our universe. Additionally, we have constrained the spread to be strictly positive. Practically speaking, it implies that we have replaced all bonds spreads which were equal or below 0 by 1 . Additionally, we use a two tailed $99 \%$ winsorization scheme for the DTS, a method developed by Dixon (1960), which implies to replace values in the tails of the distribution by the value of the 99th percentile. This way, we avoid traditional drawbacks from ERC applications where when the risk measure tends towards 0 , the weight increases drastically. Due to a poor filing of the leisure industry, with sometimes only one firm, we attach this sector to services. We are thus left with 17 distinct sectors that are presented in Appendix B. To set each as- 
set optimal weight at date $t$, we consider previous month's DTS, t-1 being the timeliest information available. To get index returns at a given date we simply multiply each bond weight by its Total Rate of Return (TRR) obtained from Merrill Lynch. ${ }^{8}$ We rebalance this long-only index once a year at the end of January, and then leave the weights drift according to market movements.

\section{$5 \quad$ Back-testing ERC indexes}

Back-tests were run over the sample for the six indexes we construct as well as the CW benchmark and EW index. Results are presented below in Table 4 while Figure 3 displays indexes total returns since the index inception date.

Table 4: Back-tests results, 12/31/1996-12/31/2015

\begin{tabular}{lcccccccc}
\hline & CW & EW & Bond parity & Issuer parity & $\begin{array}{c}\text { Issuer parity } \\
\text { within }\end{array}$ & Sector parity & $\begin{array}{c}\text { Sector parity } \\
\text { within }\end{array}$ & Full parity \\
\hline Total returns & $165 \%$ & $174 \%$ & $107 \%$ & $143 \%$ & $127 \%$ & $209 \%$ & $149 \%$ & $132 \%$ \\
Ann. returns & $5.25 \%$ & $5.45 \%$ & $3.91 \% * *$ & $4.79 \%$ & $4.41 \%^{*}$ & $6.12 \% * * *$ & $4.93 \%$ & $4.54 \%$ \\
Volatility & $3.97 \%$ & $4.15 \%$ & $1.93 \%^{* * *}$ & $2.59 \%^{* * *}$ & $2.22 \%^{* * *}$ & $4.02 \%$ & $2.67 \%^{* * *}$ & $2.27 \%^{* * *}$ \\
Sharpe ratio & 0.77 & 0.79 & 0.89 & 1.00 & 1.00 & 0.98 & 1.02 & 1.03 \\
Tracking error & - & $0.53 \%$ & $2.33 \%$ & $1.86 \%$ & $2.21 \%$ & $1.12 \%$ & $1.94 \%$ & $2.24 \%$ \\
Alpha & - & 0.00 & $0.13^{* * *}$ & $0.13^{* * *}$ & $0.15^{* * *}$ & $0.08^{* * *}$ & $0.14^{* * *}$ & $0.15^{* * *}$ \\
Beta & 1 & $1.04^{* * *}$ & $0.45^{* * *}$ & $0.60^{* * *}$ & $0.50^{* * *}$ & $0.97^{* * *}$ & $0.61^{* * *}$ & $0.51^{* * *}$ \\
Treynor ratio & 3.06 & 3.14 & 3.86 & 4.31 & 4.43 & 4.05 & 4.50 & 4.65 \\
Max. drawdown & $-11.37 \%$ & $-12.35 \%$ & $-3.26 \%$ & $-5.06 \%$ & $-3.91 \%$ & $-9.23 \%$ & $-5.09 \%$ & $-4.13 \%$ \\
Spread & 125.20 & 130.70 & 42.35 & 97.49 & 81.27 & 122.91 & 99.22 & 83.09 \\
Rating & $\mathrm{A} / \mathrm{BBB}$ & $\mathrm{A} / \mathrm{BBB}$ & $\mathrm{AA} / \mathrm{A}$ & $\mathrm{A} / \mathrm{BBB}$ & $\mathrm{AA} / \mathrm{A}$ & $\mathrm{A} / \mathrm{BBB}$ & $\mathrm{A} / \mathrm{BBB}$ & $\mathrm{A} / \mathrm{BBB}$ \\
Duration & 5.37 & 5.44 & 3.29 & 4.28 & 3.63 & 5.65 & 4.37 & 3.72 \\
Tears to maturity & 7.88 & 8.14 & 4.02 & 5.60 & 4.57 & 8.57 & 5.81 & 4.74 \\
HH index & 0.15 & 0.32 & 0.11 & 0.86 & 0.67 & 0.34 & 1.39 & 1.08 \\
Ann. two way & & & & & & & & 7.39 \\
turnover & $4.89 \%$ & $3.82 \%$ & $6.87 \%$ & $7.55 \%$ & $7.79 \%$ & $5.38 \%$ & $7.61 \%$ & $7.84 \%$ \\
\hline
\end{tabular}

Notes: The benchmark refers to the capitalization-weighted index from Merrill Lynch. 3 Months T-bill secondary market rates from the Federal Reserve Bank of St Loris database were averad over the study periol to obtain a risk-free rate of $2.19 \%$. Sharpe ratio corresponds to the return of the portfolio minus the risk-free rate, divided by the sto the the p-values for dificed tracking error is the standard devation of the difference between the returns of a portfolio and a given benchmark. (Annualized) alpha and beta are reported from the regression of indexes returns on the benchmark. Treynor ratio represents the difference between the return of a portfolio and the risk free rate, divided by its beta (so adjusted from duration risk). Maximum drawdown (Max. drawdown) represents the maximum loss during a specific period of time delimited by the highest peak and the lowest trough. Ratings were computed from Morningstar (c) methodology. Spread, ratings, duration, number of years to maturity are averaged over the period. The Herfindahl-Hirschman (HH) index is a measure of concentration, more precisely it is the sum of squared weights, and thus read as the lower the least concentrated. Two way turnover was computed by summing the absolute weight variations between $\mathrm{t}-1$ and $\mathrm{t}$ for each month, and then annualized. Significant at $1 \%$,

** Significant at $5 \%$,

* Significant at $10 \%$

We observe that generally speaking, and as expected by theory, the ERC principle applied on DTS is a very defensive strategy. Indeed, except for the sector parity index, volatility is almost divided by two compared to the benchmark. In terms of outperformance solely, only the sector parity index beats the benchmark. However, when turning to risk-adjusted returns appraisal, all ERC indexes outstrip the CW benchmark: applying such risk parity principle improves the risk-return profile, as shown by the systematic gains reported

\footnotetext{
${ }^{8}$ Index return calculation: $T R R_{t}=\sum_{i=1}^{n} w_{i t} T R R_{i t}$ where $\sum_{i=1}^{n} w_{i t}=1, i$ denotes a bond and $w_{i t}$ represents the weight attributed to a bond at time $\mathrm{t}$. Index value calculation: Index Value I $_{+1}=$ Index Value $_{t}\left(1+T R R_{t+1}\right)$ with Index Value $_{t}=$ 100 for $\mathrm{t}=12 / 31 / 1996$.
} 
Figure 3: Total returns

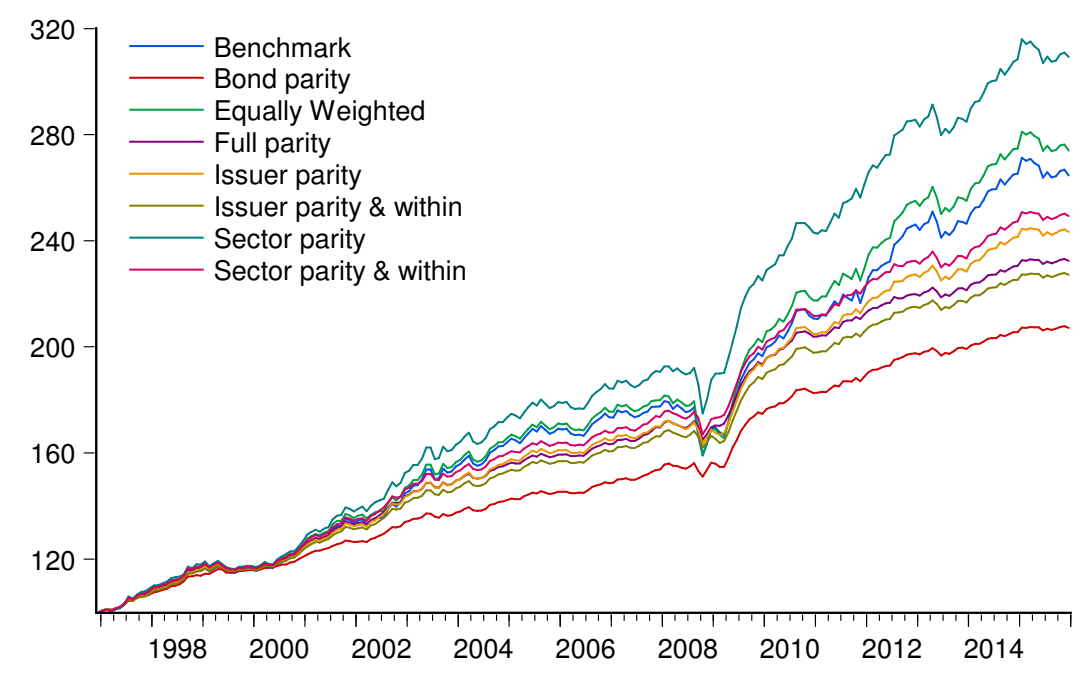

in the Sharpe and Treynor ratios. In addition, the more we move away from capitalization weights, the more obvious are the risk-adjusted performance enhancements. To illustrate, switching from issuer parity (where there is only one 'layer' of ERC strategy) to issuer parity within (that has two layers of ERC strategies and hence does not relate anymore to CW) allows substantial improvement in the Treynor ratio. This idea is reinforced by the differential in the Sharpe ratios between the sector parity and the sector parity within indexes. Following that observation it does not come as a surprise that the full parity index appears as the most compelling index. Thus, these results support that the higher the granularity, the higher the gains in the risk-return space. Another foreseen result is that both average duration and spread are sensibly shrunk through the ERC implementation on DTS. ${ }^{9}$

As far as implementation issues are concerned, general lower time to maturity reveals that the liquidity of the ERC approaches should not be deteriorated compared to the benchmark, decreasing potential concerns (Houweling and Van Zundert, 2015). We also note that using an alternative weighting scheme to capitalization does increase turnover, a result in line with the literature (Amenc et al., 2011; Maillard et al., 2010). More specifically, the higher the granularity, the higher is the rise in turnover. Still, we argue that the increase is reasonable, hampered by our parsimonious annual rebalancing rule.

\footnotetext{
${ }^{9}$ Aware that our sample period may have favored short duration bond's returns, we present duration adjusted results in Appendix C, Figure $\mathrm{C}$ and Table $\mathrm{C}$ and finds that risk-adjusted performance enhancements remain.
} 


\section{Performance analysis}

Firstly, turning to concentration issues we focus on the Herfindahl-Hirschman index displayed in Table 4, a diversification metric in terms of portfolio weights (Pola, 2016). Only the bond parity index allows achieving lower concentration than the CW benchmark, which is natural considering the index design process. Indeed, as soon as we depart from the bond level (that is focusing on issuer or sector) we are likely to encounter heterogeneity within a bucket. To explain, in order to achieve equal risk contribution within an issuer that has two bonds $A$ and $B$ with respectively $D T S_{A}=1$ and $D T S_{B}=1000$, we would have to set the weight of the asset $\mathrm{B}$ way bigger than the weight of asset $\mathrm{A}$. We argue that heterogeneity at the issuer level, a problem not faced for equities that have a unique asset for a company, can be held responsible for that fortuitous effect on bond weight concentration increase. However, we believe that the concentration issue is mitigated, considering that we tilt the portfolio towards bond issuances with the lowest DTS, thus supposed the less risky according to that measure.

Additionally, we note that generally, the maturity of the portfolio decreases when applying the ERC weighting scheme (see Table 4). This finding is in line with the existence of a short-term anomaly in the corporate bond market, evidences showing that short-dated securities tend to have higher Sharpe ratios (Aussenegg et al., 2015; Derwall et al., 2009). de Carvalho et al. (2012) argue that such phenomenon is in fact rather a low risk anomaly; analogous to the one found in the equity world. The significant risk-adjusted returns enhancements we enjoy when tilting the portfolio towards low DTS securities corroborate the existence of such low risk anomaly in the corporate fixed income market.

Figure 4: Average sectors weights over the period 12/31/1996-12/31/2015

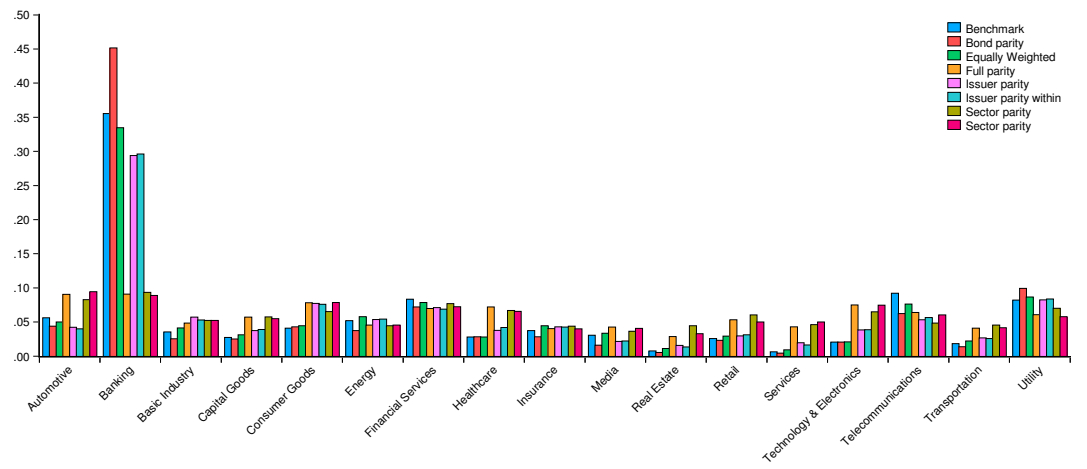


Sectors weights are presented in details in Appendix D while averaged out for the whole period above in Figure 4. As shown, the strict ERC on the bond level, by its intrinsic construction will be biased towards the industries the most represented, that is the banking industry in our case. On a more general tone, we note that introducing a sectoral layer in a risk parity framework leads to an overweighting of technology, healthcare, consumer goods, services and automotive compared to the benchmark, while banking is drastically shrunk. We thus invoke that these former sectors generally have a lower DTS. It also implies that banks are generally overweighted in traditional benchmark considering their potential risk in terms of DTS. These shifts in sectors weights raise the following question: are they the drivers of the ERC indexes outperformance? In order to answer that point, we build an auxiliary index to dissociate the sector reweighing effect from the genuine use of ERC, presented below in Table 5. Technically, it implies that we create an index where sector weights are those of the cap-weighted benchmark, and then within sectors, we apply an ERC weighting scheme based on DTS to weight issuers.

Table 5: Isolating the sector effect from the ERC application

\begin{tabular}{|c|c|c|c|}
\hline & $\begin{array}{c}\mathrm{CW} \\
\text { Sectors } C W \text { weighted, } \\
\text { Issuers } C W \text { weighted }\end{array}$ & $\begin{array}{c}\text { Sector parity } \\
\text { Sectors ERC weighted, } \\
\text { Issuers } C W \text { weighted }\end{array}$ & $\begin{array}{c}\text { Auxiliary } \\
\text { Sectors } C W \text { weighted } \\
\text { Issuers ERC weighted }\end{array}$ \\
\hline Total returns & $165 \%$ & $209 \%$ & $143 \%$ \\
\hline Ann. returns & $5.25 \%$ & $6.12 \% * * *$ & $4.79 \%$ \\
\hline Volatility & $3.97 \%$ & $4.02 \%$ & $2.60 \% * * *$ \\
\hline Sharpe ratio & 0.77 & 0.98 & 1.00 \\
\hline Tracking error & - & $1.12 \%$ & $1.81 \%$ \\
\hline Alpha & - & $0.97^{* * *}$ & $1.55^{* * *}$ \\
\hline Beta & 1 & 0.97 & 0.61 \\
\hline Treynor ratio & 3.06 & 4.05 & 4.27 \\
\hline
\end{tabular}

Notes: The benchmark refers to the capitalization-weighted index from Merrill Lynch. 3 Months T-bill secondary market rates from the Federal Reserve Bank of St Louis database were averaged over the study period to obtain a risk-free rate of $2.19 \%$. Sharpe ratio corresponds to the return of the portfolio minus the risk-free rate, divided by the standard deviation of the returns. We have computed the p-values for differences from the benchmark, using a paired t-test for the monthly returns, and a Fisher test of equality of variances. (Annualized) tracking error is the standard deviation of the difference between the returns of a portfolio and a given benchmark. (Annualized) alpha and beta are reported from the regression of indexes returns on the benchmarks. Treynor ratio represents the difference between the return of a portfolio and the risk free rate, divided by its beta (so adjusted from duration risk).

*** Significant at $1 \%$,

** Significant at $5 \%$,

* Significant at $10 \%$.

The sector parity index presented here allows quantifying how much of the risk-adjusted performance improvement is due to the simple sector reweighing. We note that the latter effect alone does add value, as supported by the rise in annualized returns, Sharpe and Treynor ratios, as well as a significant alpha compared to the benchmark. However, one could note that volatility is still 
comparable to the cap-weighting index's one. As far as the auxiliary index is concerned, it permits to quantify the benefits from using the ERC approach in itself, keeping the same sector weights as the benchmark. The risk adjusted metrics are higher than the sector parity index. Analogically, the alpha is enhanced and volatility shrunk. In short, sector reweighing does participate in the risk-adjusted performance of the indexing scheme we present: it helps to secure a certain level of returns without getting to far from the market performance, as proven by the high beta of 0.97 . Nonetheless, applying the ERC principle on a finest level (issuers) does a great job at reducing riskiness and in that matter does bring more risk-adjusted returns enhancements that the sector reweighing alone.

Figure 5: Average geographical weights over the period 12/31/1996 -12/31/2015

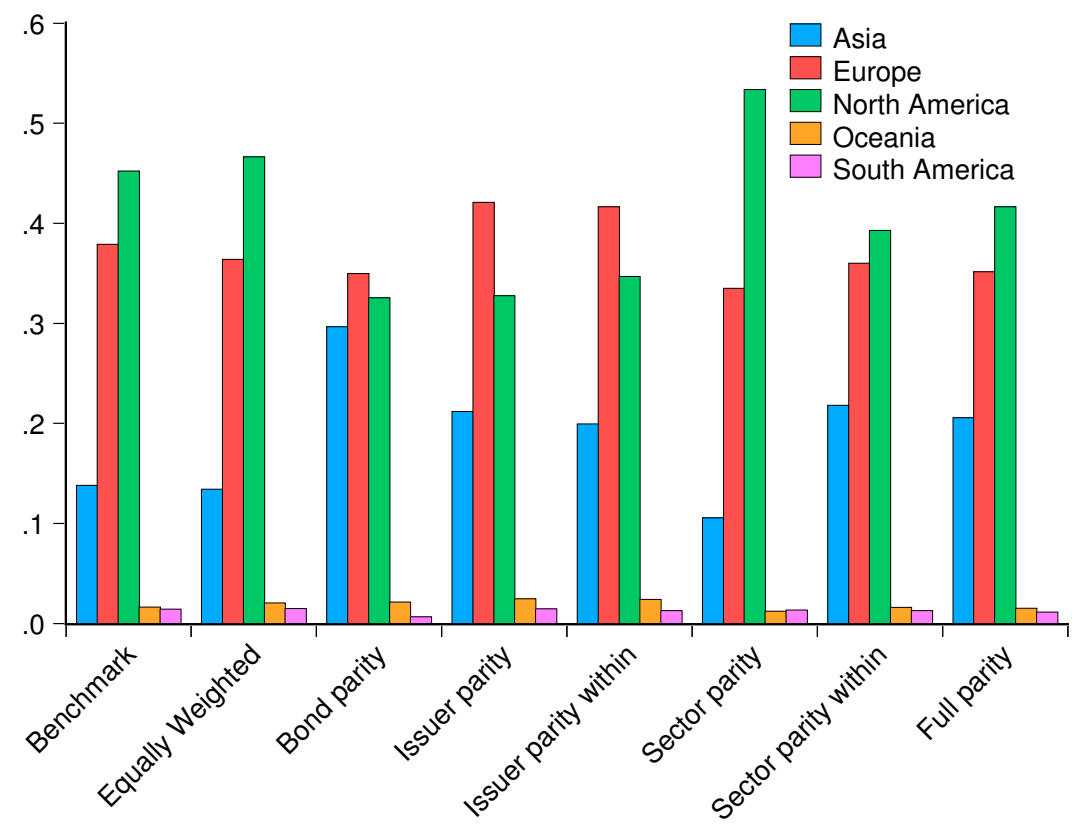

Figure 5 depicts the weights by geographical zones while presented in more details in Appendix D. We observe that both Oceania and South America are small players in the index universe while North America and Europe are systematically over-weighted compared to Asia. Still, only bond and issuer parity strategies put European securities before North American ones. When focusing on time-varying weights in Appendix D, we observe that most of the ERC indexes consistently turn away from European and North American bonds in favor of Asian securities in comparison to the CW index after the dot com bubble burst and during the subprime crisis in a more important extent. 
We are now inclined towards evaluating the ERC strategy performances robustness across the business cycle, and more specifically across different interest and spread regimes. Table 5 synthesizes the index's performances controlled for interest rate regime. The period we work on is decomposed between three distinct samples: rising, falling, and zero interest rate, in order to capture the recent era.

The first noteworthy result is the systematic improvement in the Treynor ratio. It implies that the ERC strategy delivers consistent superior risk-adjusted returns, independently of the interest rate environment. A second point we observe is the dominance of the ERC indexes that have a "within" layer. Indeed, the best results under rising rate emanate from the issuer parity and within, under falling rate the full parity index is preferred, while under the zero rate environment sector parity and within index ranks best. We now turn towards the performance of the ERC principle over different spread regimes. Indeed considering the sample period we work on, characterized by two recessions, with low yields prevailing in the fixed income world, one could wonder how much sensitive are the risk-adjusted performance improvements from a defensive strategy such as ERC to variations in business conditions, translated by corporate spreads.

Table 6: Performance across the interest rate cycle

\begin{tabular}{|c|c|c|c|c|c|c|c|c|c|}
\hline & & $\mathrm{CW}$ & $\mathrm{EW}$ & Bond parity & Issuer parity & $\begin{array}{c}\text { Issuer parity } \\
\text { and within }\end{array}$ & Sector parity & $\begin{array}{l}\text { Sector parity } \\
\text { and within }\end{array}$ & Full parity \\
\hline \multirow{6}{*}{ 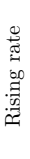 } & Ann. returns & $3.69 \%$ & $3.82 \%$ & $2.81 \%$ & $3.29 \%$ & $3.15 \%$ & $4.04 \%$ & $3.25 \%$ & $3.14 \%$ \\
\hline & Volatility & $2.63 \%$ & $2.67 \%$ & $1.41 \%$ & $1.96 \%$ & $1.68 \%$ & $2.95 \%$ & $2.11 \%$ & $1.81 \%$ \\
\hline & Sharpe ratio & 0.57 & 0.61 & 0.44 & 0.56 & 0.57 & 0.63 & 0.50 & 0.52 \\
\hline & $\mathrm{TE}$ & - & $0.18 \%$ & $2.36 \%$ & $2.14 \%$ & $2.40 \%$ & $1.35 \%$ & $2.28 \%$ & $2.47 \%$ \\
\hline & Beta & 1.00 & 1.01 & 0.49 & 0.72 & 0.61 & 1.11 & 0.77 & 0.65 \\
\hline & Treynor ratio & 1.97 & 2.07 & 2.21 & 2.17 & 2.33 & 2.09 & 1.99 & 2.17 \\
\hline \multirow{6}{*}{ 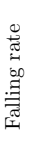 } & Ann. returns & $5.79 \%$ & $5.85 \%$ & $4.53 \%$ & $5.59 \%$ & $5.40 \%$ & $6.79 \%$ & $5.99 \%$ & $5.74 \%$ \\
\hline & Volatility & $3.23 \%$ & $3.23 \%$ & $1.58 \%$ & $2.34 \%$ & $2.04 \%$ & $3.52 \%$ & $2.52 \%$ & $2.20 \%$ \\
\hline & Sharpe ratio & 1.11 & 1.13 & 1.48 & 1.45 & 1.58 & 1.31 & 1.51 & 1.62 \\
\hline & $\mathrm{TE}$ & - & $0.30 \%$ & $2.02 \%$ & $1.45 \%$ & $1.70 \%$ & $0.74 \%$ & $1.39 \%$ & $1.61 \%$ \\
\hline & Beta & 1.00 & 1.00 & 0.42 & 0.66 & 0.56 & 1.07 & 0.71 & 0.61 \\
\hline & Treynor ratio & 4.07 & 4.15 & 6.63 & 5.85 & 6.57 & 4.75 & 5.99 & 6.62 \\
\hline \multirow{6}{*}{ 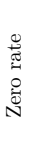 } & Ann. returns & $5.79 \%$ & $6.15 \%$ & $4.00 \%$ & $4.97 \%$ & $4.26 \%$ & $6.81 \%$ & $4.98 \%$ & $4.27 \%$ \\
\hline & Volatility & $5.21 \%$ & $5.55 \%$ & $2.46 \%$ & $3.14 \%$ & $2.65 \%$ & $4.99 \%$ & $3.10 \%$ & $2.58 \%$ \\
\hline & Sharpe ratio & 0.69 & 0.71 & 0.74 & 0.89 & 0.78 & 0.93 & 0.90 & 0.81 \\
\hline & $\mathrm{TE}$ & - & $0.81 \%$ & $3.03 \%$ & $2.60 \%$ & $3.05 \%$ & $1.63 \%$ & $2.77 \%$ & $3.16 \%$ \\
\hline & Beta & 1.00 & 1.06 & 0.44 & 0.56 & 0.46 & 0.91 & 0.54 & 0.44 \\
\hline & Treynor ratio & 4.07 & 4.20 & 5.16 & 5.84 & 5.54 & 5.60 & 6.08 & 5.83 \\
\hline
\end{tabular}

Notes: We use the 3 months T-bill Secondary Market from the Federal Reserve Bank of St Louis database. Phases were identified qualitatively. Rising T-Bill rate regime corresponds to periods from 09/30/1998 to 10/31/2000, 05/31/2004-02/28/2007 and since 09/30/2015. Falling T-bill rate regime corresponds to 12/31/1996-08/31/1998, 11/30/2000-04/30/2004 and 03/31/2007-08/31/2008. Between 09/30/2008 and 09/30/2015 we consider that we are in the zero T-bill rate regime.

Table 6 shows that generally, most of the gains from using an ERC principle on corporate bonds are achieved during rising spread regime, as shown by the Treynor ratio gains compared to the CW benchmark. Volatility is always reduced though, except for the sector parity index, which is actually the closest to the benchmark in terms of weights. Put together with the results from Table 
Table 7: Performance across different spread regimes

\begin{tabular}{|c|c|c|c|c|c|c|c|c|c|}
\hline & & $\mathrm{CW}$ & EW & Bond parity & Issuer parity & $\begin{array}{c}\text { Issuer parity } \\
\text { within }\end{array}$ & Sector parity & $\begin{array}{l}\text { Sector parity } \\
\text { within }\end{array}$ & Full parity \\
\hline \multirow{6}{*}{ 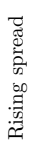 } & Ann. returns & $4.47 \%$ & $4.53 \%$ & $4.31 \%$ & $4.96 \%$ & $4.75 \%$ & $6.22 \%$ & $5.47 \%$ & $5.22 \%$ \\
\hline & Volatility & $4.35 \%$ & $4.56 \%$ & $2.06 \%$ & $2.70 \%$ & $2.37 \%$ & $4.35 \%$ & $2.89 \%$ & $2.51 \%$ \\
\hline & Sharpe ratio & 0.52 & 0.51 & 1.03 & A1.03 & 1.08 & 0.93 & 1.14 & 1.21 \\
\hline & $\mathrm{TE}$ & - & $0.61 \%$ & $2.63 \%$ & $2.32 \%$ & $2.60 \%$ & $1.55 \%$ & $2.38 \%$ & $2.60 \%$ \\
\hline & Beta & 1.00 & 1.04 & 0.43 & 0.55 & 0.47 & 0.94 & 0.57 & 0.49 \\
\hline & Treynor ratio & 2.75 & 2.70 & 6.03 & 5.89 & 6.46 & 4.81 & 6.5 & 7.18 \\
\hline \multirow{6}{*}{ 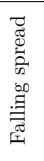 } & Ann. returns & $9.55 \%$ & $10.18 \%$ & $5.48 \%$ & $6.93 \%$ & $6.26 \%$ & $9.18 \%$ & $6.50 \%$ & $5.88 \%$ \\
\hline & Volatility & $4.41 \%$ & $4.72 \%$ & $2.32 \%$ & $3.15 \%$ & $2.69 \%$ & $4.59 \%$ & $3.14 \%$ & $2.65 \%$ \\
\hline & Sharpe ratio & 1.67 & 1.69 & 1.42 & 1.50 & 1.51 & 1.52 & 1.37 & 1.39 \\
\hline & $\mathrm{TE}$ & - & $0.75 \%$ & $2.43 \%$ & $1.67 \%$ & $2.14 \%$ & $0.63 \%$ & $1.73 \%$ & $2.19 \%$ \\
\hline & Beta & 1.00 & 1.06 & 0.49 & 0.68 & 0.57 & 1.03 & 0.68 & 0.56 \\
\hline & Treynor ratio & 7.83 & 8.00 & 7.74 & 7.62 & 7.98 & 7.23 & 7.08 & 7.45 \\
\hline \multirow{6}{*}{ 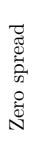 } & Ann. returns & $3.69 \%$ & $3.80 \%$ & $2.41 \%$ & $3.22 \%$ & $2.81 \%$ & $4.08 \%$ & $3.21 \%$ & $2.80 \%$ \\
\hline & Volatility & $2.96 \%$ & $2.96 \%$ & $1.34 \%$ & $1.97 \%$ & $1.55 \%$ & $3.05 \%$ & $1.96 \%$ & $1.54 \%$ \\
\hline & Sharpe ratio & 0.51 & 0.54 & 0.17 & 0.52 & 0.40 & 0.62 & 0.52 & 0.40 \\
\hline & $\mathrm{TE}$ & - & $0.15 \%$ & $1.70 \%$ & $1.12 \%$ & $1.53 \%$ & $0.45 \%$ & $1.17 \%$ & $1.55 \%$ \\
\hline & Beta & 1.00 & 1.00 & 0.44 & 0.65 & 0.50 & 1.02 & 0.64 & 0.50 \\
\hline & Treynor ratio & 1.97 & 2.08 & 1.58 & 2.31 & 2.16 & 2.32 & 2.33 & 2.17 \\
\hline
\end{tabular}

5 , the indexing schemes we present turn out to be very robust to a deteriorated economic context (rising corporate spreads combined with decreasing interest rate), with risk-adjusted performances higher than the cap-weighted benchmark. In all, these analyses carried on changing business environments again put in light the defensive feature intrinsic to the ERC strategy, and more generally risk parity weighting schemes. Let us now compare the different indexes in terms of DTS. From Figure 6, we observe that indexes can be loosely divided between two groups: the benchmark, equally weighted and sector parity indexes (that we could qualify as "high beta" strategies) versus the other indexes. Most importantly, we observe that adding a parity "within" component considerably decreases overall risk, an argument in favor of higher granularity.

Finally, in order to better apprehend the performance drivers behind the application of the ERC principle on DTS, we study the exposure of this strategy to traditional bond specific risks, namely credit and interest rate. To capture the former we decide to employ a DEFAULT risk factor (that relates to the credit spread) and a LOW risk factor to discriminate between issuers predicted solvency on the basis of their ratings from credit rating agencies. The DEFAULT factor is defined on a portfolio that is long the Barclays Long U.S. Corporate Investment Grade Index and short the 10-20 years Barclays U.S. treasuries Index as in Gebhardt et al. (2005). ${ }^{10}$ We construct a LOW RISK factor following Houweling and Van Zundert (2015) by selecting bonds rated from AAA to Afrom the G0LC (Merrill Lynch investment grade benchmark), and then among those, keep the $10 \%$ with the shorter maturity, that is below 1.9 years on average

\footnotetext{
${ }^{10}$ We do not use the G0LC to avoid high correlation between the CW benchmark and the DEFAULT factor.
} 
Figure 6: DTS for each index

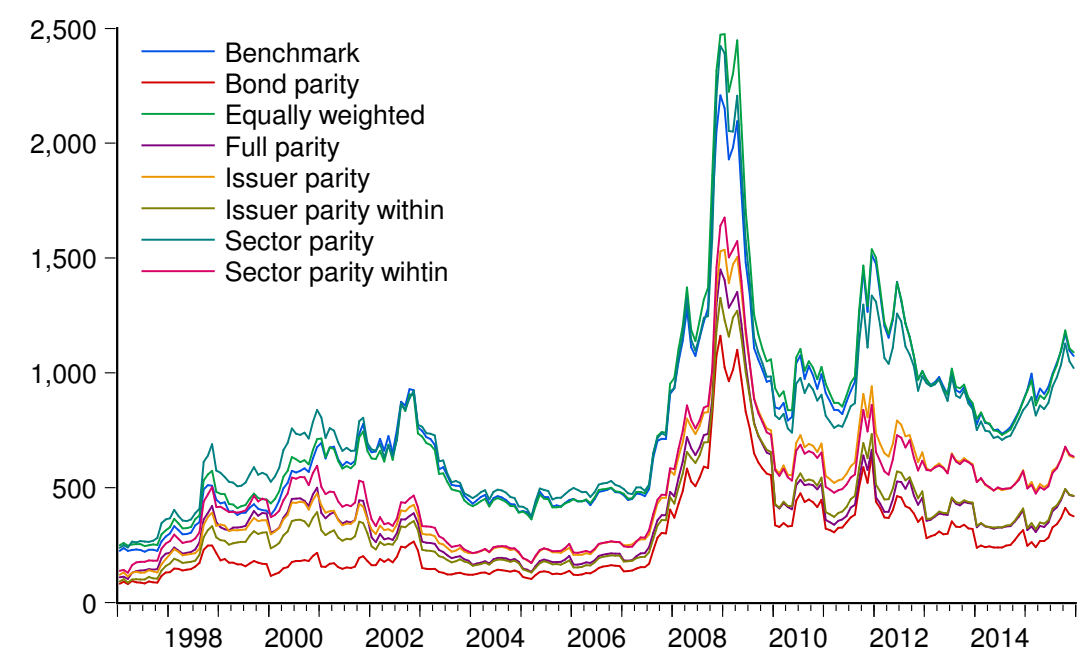

over the period, with rolling threshold value across time. As far as interest rate risk is concerned, we are keen to incorporate the term structure in our factor analysis, characterized by SHIFT, TWIST and BUTTERFLY variations in the yield curve. Regarding the term-structure related factors, we isolate the three components from a Principal Component Analysis applied to U.S. Treasuries market yield change, using maturities ranging from 1 month to 30 years (see Figure E1 in Appendix E). We note that these three factors allow explaining $97 \%$ of the variability of the yield curve (see Table E1 in Appendix E). It is generally argued that SHIFT is the most important determinant amongst the three term-structure parameters, a result corroborated by our findings where SHIFT accounts for $72 \%$ of the explained variance (Litterman and Scheinkman, 1991). Using historical monthly data from $12 / 31 / 1996$ to $12 / 31 / 2015$, we manage to obtain the factor loadings of the shift, twist and butterfly components on the U.S. treasuries yield from different maturities, which allows us to reconstruct these three factors (see Table E2 and Figure E2 in Appendix E). ${ }^{11}$ Factor analysis results are presented in Table 7; monthly index's return minus the risk free rate is the dependent variable in each regression.

As a matter of fact, our risk model appears correctly specified, since most of the factors we chose are significant across specifications. Still, here we focus on the relative exposure of the ERC indexes to risk factors compared to the benchmark. On a general note, we argue that applying the risk parity principle on DTS allows to moderate traditional fixed-income risk exposures compared

${ }^{11}$ More precisely we employ yield for $1 \mathrm{M}, 3 \mathrm{M}, 6 \mathrm{M}, 1 \mathrm{Y}, 2 \mathrm{Y}, 3 \mathrm{Y}, 5 \mathrm{Y}, 7 \mathrm{Y}, 10 \mathrm{Y}, 20 \mathrm{Y}, 30 \mathrm{Y}$. 
Table 8: Factor exposures

\begin{tabular}{lcccccccc}
\hline & CW & EW & Bond parity & Issuer parity & $\begin{array}{c}\text { Issuer parity } \\
\text { within }\end{array}$ & Sector parity & $\begin{array}{c}\text { Sector parity } \\
\text { within }\end{array}$ & Full parity \\
\hline Alpha & $-3.04^{* * *}$ & $-3.36^{* * *}$ & $-1.64^{* * *}$ & $-1.33^{* *}$ & $-1.32^{* * *}$ & $-1.71^{* *}$ & $-1.11^{*}$ & $-1.08^{* *}$ \\
Default risk & $0.17^{* * *}$ & $0.17^{* * *}$ & $0.04^{* * *}$ & $0.05^{* *}$ & $0.03^{*}$ & $0.14^{* * *}$ & $0.05^{* *}$ & $0.03^{*}$ \\
Low risk & $0.17^{* * *}$ & $0.19^{* * *}$ & $0.09^{* *}$ & $0.11^{* * *}$ & $0.10^{* * *}$ & $0.16^{* * *}$ & $0.11^{* * *}$ & $0.09^{* * *}$ \\
Shift & $0.47^{* * *}$ & $0.41^{* * *}$ & $0.25^{* * *}$ & $0.39^{* * *}$ & $0.33^{* * *}$ & $0.61^{* * *}$ & $0.42^{* * *}$ & $0.35^{* * *}$ \\
Twist & $-0.92^{* * *}$ & $-0.93^{* * *}$ & $-0.29^{* * *}$ & $-0.56^{* * *}$ & $-0.41^{* * *}$ & $-1.04^{* * *}$ & $-0.60^{* * *}$ & $-0.45^{* * *}$ \\
Butterfly & $-0.80^{* *}$ & $-0.84^{* *}$ & -0.21 & -0.41 & -0.27 & $-0.97^{* *}$ & -0.39 & -0.21 \\
\hline F-stat & 118.37 & 122.24 & 77.36 & 57.90 & 60.39 & 77.62 & 53.27 & 55.05 \\
$\mathrm{R}^{2}$ & 0.73 & 0.73 & 0.64 & 0.57 & 0.58 & 0.64 & 0.55 & 0.55 \\
\hline \multicolumn{7}{l}{ Notes: Alpha is annualized. } \\
$\quad$
\end{tabular}

to the capitalization weighted benchmark: absolute coefficients are generally shrunk, except for the sector parity index, the closest one to capitalization weighting. Default risk is mitigated, sensitivity of returns to yield curve shifts and twists weaken while its curvature does not appear to drive excess returns, the butterfly factor being insignificant in most cases for the ERC indexes. More surprisingly, we note that exposure to the low risk premium is systematically diminished, despite that we purposely tilt the portfolio towards narrow spread and low duration bonds. One possible explanation could be that high ratings do not necessarily stand for low DTS.

\section{Conclusion}

Flaws associated to traditional capitalization-weighting have forced investors to reconsider their asset allocation, and therefore they turned to new alternative weighting schemes. Risk-based methods are an integral part of this evolution and have appeared to work particularly well for the past few years, talking advantage of the low risk environment. In this paper, we take a closer look to the application of an ERC principle on corporate bonds and present a way to implement it. More specifically, our contribution is twofold: we give evidence that using block matrices in the optimization process simplify the analytics for weight derivation while providing valuable results in term of risk-adjusted performance enhancements. Secondly, we show that DTS can be used as a coherent bond risk measure as it satisfies the required mathematical properties. We also provide empirical evidences to corroborate this theoretical finding by highlighting the positive relationship between DTS and excess returns volatility. Acknowledging the relevance of DTS as a risk measure, we propose different index weighting schemes based on that measure and put in light the subsequent risk-return profile improvements. Our findings show that ERC is clearly a defensive strategy, volatility and drawdown being noticeably reduced. The superiority of the whole set of strategies presented here (bond, issuer, sector parity) in terms of riskadjusted metrics compared to traditional weighting schemes authenticates the 
presence of low risk anomaly in the corporate bond market. These results are robust to changing economic environment, risk-adjusted returns being generally equal or above the benchmark's. We also demonstrate that sector reweighing and factor exposure to traditional fixed income risks cannot be held responsible for performance enhancement. Our study tends to demonstrate that the higher the number of parity layers the granularity - the higher are the risk-return profile improvements. Finally, we stress that the ERC principle is flexible in the sense that correlation blocks may be built on sectors, issuer and bonds, but that they can also be easily translated to other buckets, such as countries, currency or even country $\mathrm{x}$ sector. We argue that this risk-based indexing scheme lies between the heuristic EW scheme and more complex risk modeling based meth-

ods, freed up from estimation issues. On the whole, our findings attest that this parsimonious strategy allows improving risk-adjusted returns at a cheap cost.

\section{References}

N. Amenc, F. Goltz, L. Martellini, and L. Tang. Improved beta? Journal of Indexes, 14(1):10-19, 2011.

R. D. Arnott, J. Hsu, and P. Moore. Fundamental indexation. Financial Analysts Journal, 61(2):83-99, 2005.

P. Artzner, F. Delbaen, J. M. Eber, and D. Heath. Coherent measures of risk. Mathematical finance, 9(3):203-228, 1999.

W. Aussenegg, L. Goetz, and R. Jelic. Common factors in the performance of european corporate bonds: Evidence before and after the financial crisis. European Financial Management, 21(2):265-308, 2015.

J. Bai and P. Collin-Dufresne. The CDS-bond basis. Available at SSRN, 2013.

T. M. Barnhill Jr and W. F. Maxwell. Modeling correlated market and credit risk in fixed income portfolios. Journal of Banking \& Finance, 26(2):347-374, 2002 .

A. Ben Dor, L.. Dynkin, J. Hyman, P. Houweling, E. van Leeuwen, and O. Penninga. DTS (Duration Times Spread). Journal of Portfolio Management, 33: 77-100, 2007.

R. Blanco, S. Brennan, and I. W. Marsh. An empirical analysis of the dynamic relation between investment grade bonds and credit default swaps. The Journal of Finance, 60(5):2255-2281, 2005.

Z. Bodie, A. Kane, and A. J. Marcus. Investments (6th edition). Boston: McGraw-Hill, 2004.

B. Bruder and T. Roncalli. Managing risk exposures using the risk budgeting approach. Available at SSRN, 2012. 
B. Bruder, P. Hereil, and T. Roncalli. Managing sovereign credit risk in bond portfolios. Journal of Advanced Studies in Finance, 3(1):5-26, 2012.

Z. Cazalet, P. Grison, and T. Roncalli. The smart beta indexing puzzle. The Journal of Index Investing, 5(1):97-119, 2013.

D. B. Chaves, J. C. Hsu, F. Li, and O. Shakernia. Risk parity portfolio vs other asset allocation heuristic portfolios. Journal of Investing, 20(1):108-118, 2011.

Y. Choueifaty and Y. Coignard. Toward maximum diversification. Journal of Portfolio Management, 35(1):40-51, 2008.

R. L. de Carvalho, X. Lu, and P. Moulin. Demystifying equity risk-based strategies: A simple alpha plus beta description. Journal of Portfolio Management, 38(3):56-70, 2012.

M. de Jong and L. Stagnol. A fundamental bond index including solvency criteria. Journal of Asset Management, 17(4):280-294, 2016.

M. de Jong and H. Wu. Fundamental indexation for bond markets. The Journal of Risk Finance, 15(3):264-274, 2014.

J. Derwall, J. Huij, and G. J. De Zwart. The short-term corporate bond anomaly. Available at SSRN, 2009.

D. Disatnik and S. Katz. Portfolio optimization using a block structure for the covariance matrix. Journal of Business Finance and Accounting, 39(5-6): 806-843, 2012.

W. J. Dixon. Simplified estimation from censored normal samples. The Annals of Mathematical Statistics, 31(2):385-391, 1960.

H. Gatfaoui. Credit risk and market risk: Analyzing US. credit spreads. Available at SSRN, 2008.

W. R. Gebhardt, S. Hvidkjaer, and B. Swaminathan. The cross-section of expected corporate bond returns: Betas or characteristics? Journal of Financial Economics, 75(1):85-114, 2005.

P. S. Hagan, D. Kumar, A. S. Lesniewski, and D. E. Woodward. Managing smile risk. Wilmott Magazine, July, 2002.

R. A. Haugen and N. L. Baker. The efficient market inefficiency of capitalizationweighted stock portfolios. Journal of Portfolio Management, 17(3):35-40, 1991.

P. Houweling and J. Van Zundert. Factor investing in the corporate bond market. Available at SSRN, 2015.

J. C. Hsu. Cap-weighted portfolios are sub-optimal portfolios. Journal of Investment Management, 4(3):1-10, 2006. 
W. C. Kim, J. H. Kim, and F. J. Fabozzi. Deciphering robust portfolios. Journal of Banking \& Finance, 45:1-8, 2014.

R. B. Litterman and J. Scheinkman. Common factors affecting bond returns. The Journal of Fixed Income, 1(1):54-61, 1991.

F. A. Longstaff and E. S. Schwartz. A simple approach to valuing risky fixed and floating rate debt. The Journal of Finance, 50(3):789-819, 1995.

S. Maillard, T. Roncalli, and J. Teiletche. The properties of equally weighted risk contributions portfolios. Journal of Portfolio Management, 36(4):60-70, 2010.

G. Pola. On entropy and portfolio diversification. Journal of Asset Management, 14(4):218-228, 2016.

E. Qian. Risk parity portfolios: Efficient portfolios through true diversification. Panagora Asset Management, 2005.

S. Raudys. Portfolio of automated trading systems: Complexity and learning set size issues. IEEE Transactions on Neural Networks and Learning Systems, 24(3):448-459, 2013.

T. Roncalli. Introduction to Risk Parity and Budgeting. CRC Press, 2013.

A. Russo. Low-risk equity investment: From theory to practice. Journal of Asset Management, 17(4):264-279, 2016.

B. Scherer. Portfolio Construction and Risk Budgeting, Riskbooks. Riskbooks, Third Edition, 2007.

W. F. Sharpe. Capital asset prices: A theory of market equilibrium under conditions of risk. The Journal of Finance, 19(3):425-442, 1964.

Y. A. Xie, S. Liu, C. Wu, and B. Anderson. The effects of default and call risk on bond duration. Journal of Banking \& Finance, 33(9):1700-1708, 2009.

H. Zhu. An empirical comparison of credit spreads between the bond market and the credit default swap market. Journal of Financial Services Research, 29(3):211-235, 1964. 


\section{Appendices}

\section{A Derivation of ERC weights}

We construct the following six ERC indices:

- Bond parity index, where each asset brings about the same contribution to the overall risk of the portfolio

$$
w_{i t}^{\text {Bond parity }}=\frac{\frac{1}{D T S_{i t}}}{\sum_{i=1}^{n} \overline{1} \frac{1}{D T S_{i t}}}
$$

- Issuer parity index, where each company brings about the same contribution to the overall risk of the portfolio

$$
\begin{aligned}
w_{\text {Ticker } t}^{\text {Ticker parity }} & =\frac{\frac{1}{D T S_{\text {Ticker } t}}}{\sum_{\text {Ticker }=1}^{n} \frac{1}{D T S_{\text {Ticker } t}}} \\
D T S_{\text {Ticker } t} & =\frac{\sum_{i \in \text { Ticker }}^{n} w_{i t}^{M L} D T S_{\text {it }}}{\sum_{i}^{n} w_{i t}^{M L}} \\
w_{\text {it }}^{\text {Ticker parity }} & =\frac{w_{i t}^{M L}}{w_{\text {Ticker } t}^{M L}} w_{\text {Ticker } t}^{\text {Ticker parity }}
\end{aligned}
$$

- Sector parity index, following Merrill Lynch industries segmentation, where each industrial sector brings about the same contribution to the overall risk of the portfolio

$$
\begin{aligned}
w_{\text {Sector parity }}^{\text {Sector }} & =\frac{\frac{1}{D T S_{\text {Sector } t}}}{\sum_{\text {Sector }=1}^{n} \overline{D T S_{\text {Sector } t}}} \\
D T S_{\text {Sector } t} & =\frac{\sum_{i \in \text { Sector }}^{n} w_{i t}^{M L} D T S_{i t}}{\sum_{i}^{n} w_{i t}^{M L}} \\
w_{i t}^{\text {Sector parity }} & =\frac{w_{i t}^{M L}}{w_{\text {Sector } t}^{M L}} w_{\text {Sector } t}^{\text {Sector parity }}
\end{aligned}
$$

- Issuer parity and within index, where each company brings about the same contribution to the overall risk of the portfolio, and then each bond brings about the same contribution to the overall risk of the issuer

$$
\begin{gathered}
w_{\text {Ticker } t}^{\text {Ticker parity within }}=\frac{\frac{1}{D T S_{\text {Ticker } t}}}{\sum_{\text {Ticker }=1}^{n} \frac{1}{D T S_{\text {Ticker } t}}} \\
D T S_{\text {Ticker } t}=\frac{\sum_{i \in \text { Ticker }}^{n} w_{\text {it }}^{\text {Bond parity }} D T S_{i t}}{\sum_{i}^{n} w_{i t}^{\text {Bond parity }}} \\
w_{i t}^{\text {Ticker parity within }}=\frac{w_{i t}^{\text {Bond parity }} w_{\text {Ticker }}^{\text {Ticker }} \text { parity within }}{\sum_{i \in \text { Ticker }}^{n} w_{\text {it }}^{\text {Bond parity }}}
\end{gathered}
$$


- Sector parity index and within, following Merrill Lynch industries segmentation, where each industrial sector brings about the same contribution to the overall risk of the portfolio, and then issuer's risk contributions are equalized within the sector

$$
\begin{aligned}
& w_{\text {Sector parity within } t}^{\text {Sector }}=\frac{\frac{1}{D T S_{\text {Sector } t}}}{\sum_{\text {Sector }=1}^{n} \overline{D T S_{\text {Sector } t}}} \\
& D T S_{\text {Sector } t}=\frac{\sum_{i \in \text { Sector }}^{n} w_{\text {Ticker } t}^{\text {Ticker }}{ }_{\text {parity }} D T S_{i t}}{\sum_{i}^{n} w_{\text {Ticker } t}^{\text {Ticker }} \text { parity }} \\
& w_{i t}^{\text {Sector parity within }}=\frac{w_{i t}^{\text {Ticker parity }} w_{\text {Sector } t}^{\text {Sector party within }}}{\sum_{i \in \text { Sector }}^{n} w_{i t}^{\text {Ticker parity }}}
\end{aligned}
$$

- Full parity index, where sector's risk contribution are equalized, and then within each sector, each issuer has the same contribution to risk, and finally, within a given issuer all assets bring about the same risk contribution

$$
\begin{aligned}
& w_{\text {Sector } t}^{\text {Full parity }}=\frac{\frac{1}{D T S_{\text {Sector } t}}}{\sum_{\text {Sector }=1}^{n} \frac{1}{D T S_{\text {Sector } t}}} \\
& D T S_{\text {Sector } t}=\frac{\sum_{i \in \text { Sector }}^{n} w_{\text {Ticker } t}^{\text {Ticker parity within }} D T S_{i t}}{\sum_{i \in \text { Sector }}^{n}\left(\frac{w_{i t}^{M L}}{w_{\text {Tickert }}^{M L}} w_{\text {Ticker } t}^{\text {Ticker parity within }}\right)}
\end{aligned}
$$

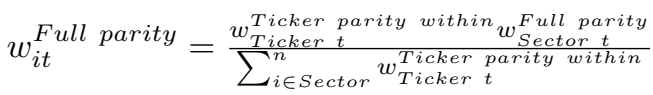




\section{B Country and industry classification}

Table B1: Country sample

\begin{tabular}{|c|c|c|c|}
\hline ISO-2 code & Country & Geographical zone & $\%$ of total bonds \\
\hline $\mathrm{AE}$ & United Arab Emirates & Asia & $0.47 \%$ \\
\hline $\mathrm{AT}$ & Austria & Europe & $0.43 \%$ \\
\hline $\mathrm{AU}$ & Australia & Oceania & $2.76 \%$ \\
\hline $\mathrm{BE}$ & Belgium & Europe & $0.70 \%$ \\
\hline $\mathrm{BM}$ & Bermuda & North America & $0.13 \%$ \\
\hline $\mathrm{BR}$ & Brazil & South America & $0.89 \%$ \\
\hline $\mathrm{CA}$ & Canada & North America & $4.22 \%$ \\
\hline $\mathrm{CH}$ & Switzerland & Europe & $1.39 \%$ \\
\hline CL & Chile & South America & $0.28 \%$ \\
\hline $\mathrm{CN}$ & China & Asia & $1.36 \%$ \\
\hline $\mathrm{CZ}$ & Czech Republic & Europe & $0.07 \%$ \\
\hline $\mathrm{DE}$ & Germany & Europe & $5.23 \%$ \\
\hline DK & Denmark & Europe & $0.45 \%$ \\
\hline ES & Spain & Europe & $1.69 \%$ \\
\hline FI & Finland & Europe & $0.26 \%$ \\
\hline FR & France & Europe & $6.43 \%$ \\
\hline GB & United Kingdom & Europe & $8.76 \%$ \\
\hline GR & Greece & Europe & $0.09 \%$ \\
\hline HK & Hong Kong & Asia & $0.64 \%$ \\
\hline $\mathrm{HU}$ & Hungary & Europe & $0.03 \%$ \\
\hline IE & Ireland & Europe & $0.77 \%$ \\
\hline IN & India & Asia & $0.35 \%$ \\
\hline IS & Iceland & Europe & $0.05 \%$ \\
\hline IT & Italy & Europe & $2.16 \%$ \\
\hline JE & Jersey & Europe & $0.23 \%$ \\
\hline JP & Japan & Asia & $6.31 \%$ \\
\hline $\mathrm{KR}$ & Korea. Republic of & Asia & $0.52 \%$ \\
\hline KY & Cayman Islands & South America & $0.47 \%$ \\
\hline $\mathrm{LU}$ & Luxembourg & Europe & $0.82 \%$ \\
\hline MX & Mexico & South America & $0.98 \%$ \\
\hline MY & Malaysia & Asia & $0.16 \%$ \\
\hline NL & Netherlands & Europe & $5.48 \%$ \\
\hline $\mathrm{NO}$ & Norway & Europe & $0.56 \%$ \\
\hline NZ & New Zealand & Oceania & $0.11 \%$ \\
\hline PL & Poland & Europe & $0.07 \%$ \\
\hline $\mathrm{PT}$ & Portugal & Europe & $0.25 \%$ \\
\hline QA & Qatar & Asia & $0.20 \%$ \\
\hline RU & Russian Federation & Europe & $0.70 \%$ \\
\hline SA & Saudi Arabia & Asia & $0.06 \%$ \\
\hline $\mathrm{SE}$ & Sweden & Europe & $1.19 \%$ \\
\hline SG & Singapore & Asia & $0.32 \%$ \\
\hline US & United States & North America & $41.97 \%$ \\
\hline
\end{tabular}


Table B2: Industry classification

\begin{tabular}{|c|c|c|c|}
\hline SectorLevel1 & SectorLevel2 & SectorLevel3 & SectorLevel4 \\
\hline & Financial & Banking & Banking \\
\hline & & & $\begin{array}{c}\text { Brokerage } \\
\end{array}$ \\
\hline & & Financial Services & Cons/Comm/Lease Financing \\
\hline & & & $\begin{array}{c}\text { Investments \& Misc Financial Services } \\
\text { Insurance Brokerage }\end{array}$ \\
\hline & Financial & & Life Insurance \\
\hline & & 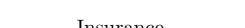 & Monoline Insurance \\
\hline & & insurance & $\begin{array}{l}\text { Multi-Line Insurance } \\
\text { P\&C }\end{array}$ \\
\hline & & & Reinsurance \\
\hline & & & Auto Loans \\
\hline & & Automotive & $\begin{array}{c}\text { Auto Parts \& Equipment } \\
\text { Automakers }\end{array}$ \\
\hline & & & $\begin{array}{l}\text { Automakers } \\
\text { Building \& Construction }\end{array}$ \\
\hline & & & Building Materials \\
\hline & & Basic industry & $\begin{array}{l}\text { Chemicals } \\
\text { Forestry/Paper }\end{array}$ \\
\hline & & & $\begin{array}{l}\text { Forestry/Paper } \\
\text { Metals/Mining Excluding Steel }\end{array}$ \\
\hline & & & Steel Producers/Products \\
\hline & & & Aerospace Defense \\
\hline & & Capital Goods & Diversified Capital Goods \\
\hline & & & Machinery \\
\hline & & & $\begin{array}{l}\text { Packaging } \\
\text { Beverage }\end{array}$ \\
\hline & & & Food - Wholesale \\
\hline & & Consumer Goods & $\begin{array}{c}\text { Personal \& Household Products } \\
\text { Tobacco }\end{array}$ \\
\hline & & & $\begin{array}{l}\text { Energy - Exploration \& Production } \\
\text { Gas Distribution }\end{array}$ \\
\hline & & Energy & Integrated Energy \\
\hline & & & Oil Field Equipment \& Services \\
\hline & & & Oil Refining \& Marketing \\
\hline & & & Health Facilities \\
\hline & & & Health Services \\
\hline \multirow{34}{*}{ Corporate } & & Healthcare & Managed Care \\
\hline & & & Medical Products \\
\hline & & & Pharmaceuticals \\
\hline & Industrials & & Gaming \\
\hline & & Leisure & Hotels \\
\hline & & & Recreation \& Travel \\
\hline & & & $\begin{array}{c}\text { Advertising } \\
\text { C }\end{array}$ \\
\hline & & Media & $\begin{array}{l}\text { Cable \& Satellite TV } \\
\text { Media - Diversified }\end{array}$ \\
\hline & & & Media Content \\
\hline & & & Printing \& Publishing \\
\hline & & & Housing Association \\
\hline & & Real Estate & RealEstate Dev \& Mgt \\
\hline & & & REITs \\
\hline & & & Department Stores \\
\hline & & & Discount Stores \\
\hline & & Retail & Food \& Drug Retailers \\
\hline & & & Restaurants \\
\hline & & & Specialty Retail \\
\hline & & Services & Environmental \\
\hline & & & Support-Services \\
\hline & & & Electronics \\
\hline & & Technology \& Electronics & Software/Services \\
\hline & & & Tech Hardware \& Equipment \\
\hline & & & Telecom - Satellite \\
\hline & & Telecommunications & Telecom - Wireless \\
\hline & & & Telecom - Wireline Integrated \& Services \\
\hline & & & Air Transportation \\
\hline & & & Rail \\
\hline & & Transportation & Transport Infrastructure/Services \\
\hline & & & Trucking \& Delivery \\
\hline & & & Electric-Distr/Trans \\
\hline & Utility & Utility & Electric-Generation \\
\hline & Utility & Utility & Electric-Integrated \\
\hline & & & Non-Electric Utilities \\
\hline
\end{tabular}




\section{Adjusting the indexes duration to match the bench- mark}

Figure C: Weight by maturity bucket

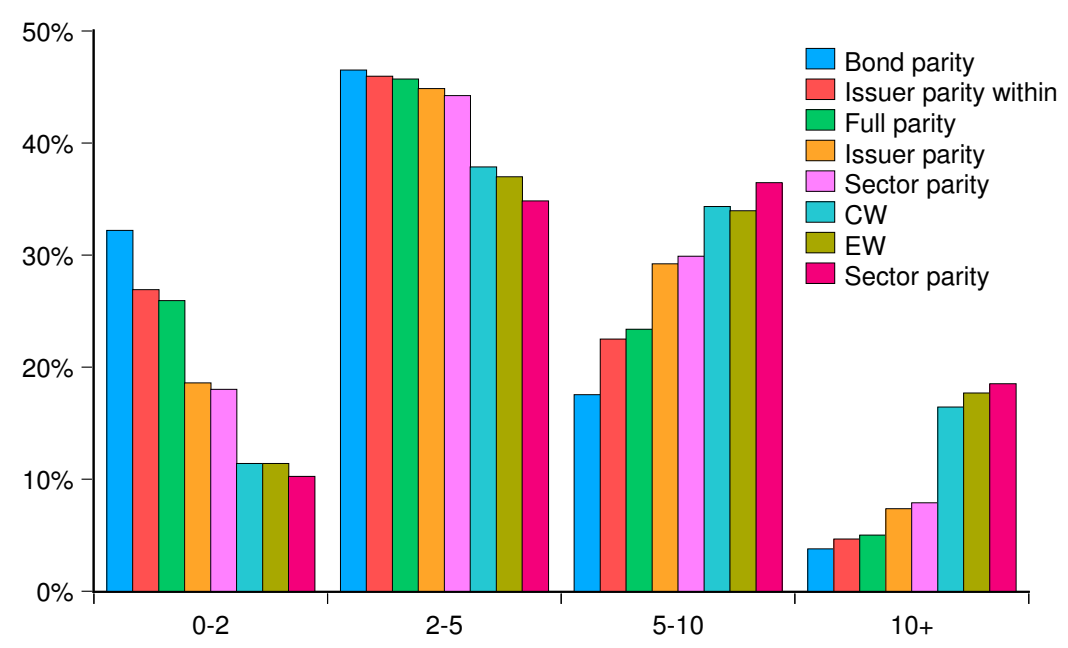

Table C: Back-tests results for duration adjusted indexes on the benchmark

\begin{tabular}{lcccccccc}
\hline & CW & EW & Bond parity & Issuer parity & Issuer parity within & Sector parity & Sector parity within & Full parity \\
\hline Total returns & $165 \%$ & $158 \%$ & $172 \%$ & $166 \%$ & $213 \%$ & $199 \%$ & $170 \%$ & $174 \%$ \\
Ann. returns & $5.25 \%$ & $5.12 \%$ & $5.41 \%$ & $5.29 \%$ & $6.19 \%$ & $5.93 \%$ & $5.36 \%$ & $5.44 \%$ \\
Volatility & $3.97 \%$ & $3.25 \%$ & $4.10 \%$ & $3.30 \%$ & $3.06 \%$ & $3.83 \%$ & $3.31 \%$ & $3.29 \%$ \\
Sharpe ratio & 0.77 & 0.90 & 0.78 & 0.94 & 1.31 & 0.98 & 0.96 & 0.99 \\
Tracking error & - & $1.33 \%$ & $0.52 \%$ & $1.47 \%$ & $1.77 \%$ & $1.09 \%$ & $1.58 \%$ & $1.62 \%$ \\
Beta & 1.00 & 0.78 & 1.02 & 0.78 & 0.70 & 0.93 & 0.77 & 0.76 \\
Treynor ratio & 3.06 & 3.76 & 3.14 & 3.99 & 5.74 & 4.04 & 4.14 & 4.28 \\
\hline
\end{tabular}




\section{Sectors and country monthly weightings}

Figure D1: Benchmark

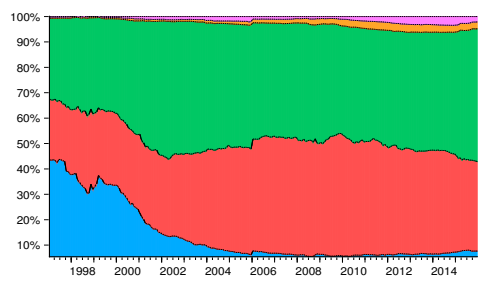

Figure D3: Bond parity

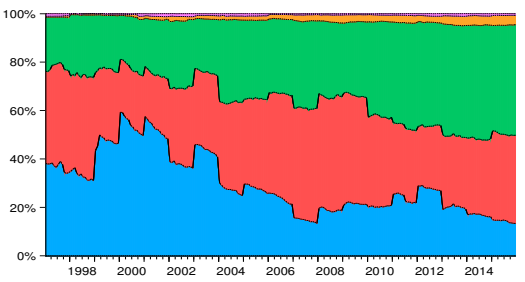

Figure D5: Issuer parity within

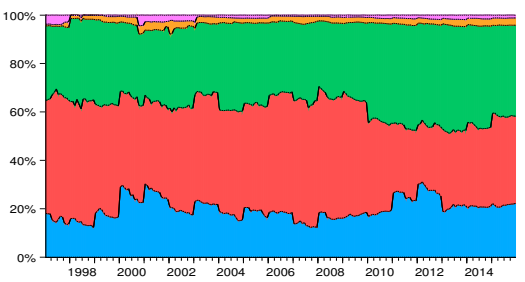

Figure D7: Sector parity within

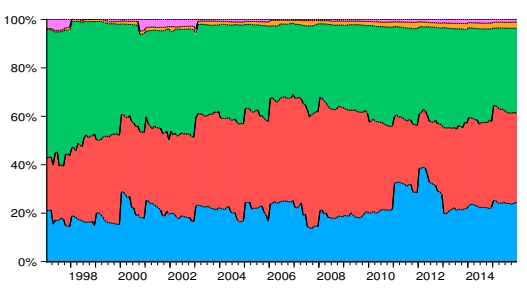

Figure D2: Equally Weighted

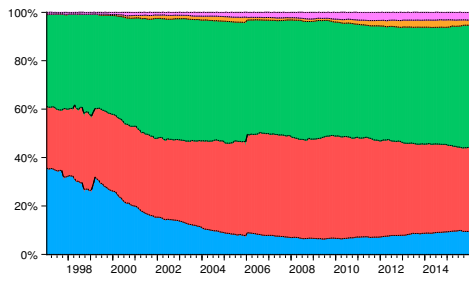

Figure D4: Issuer parity

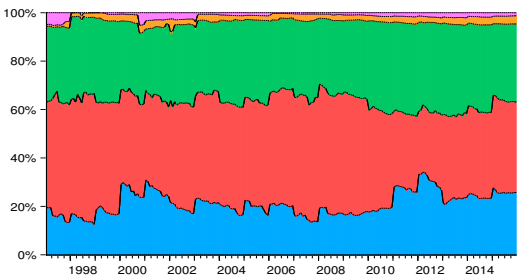

Figure D6: Sector parity

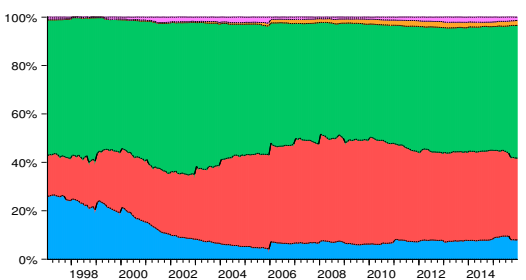

Figure D8: Full parity

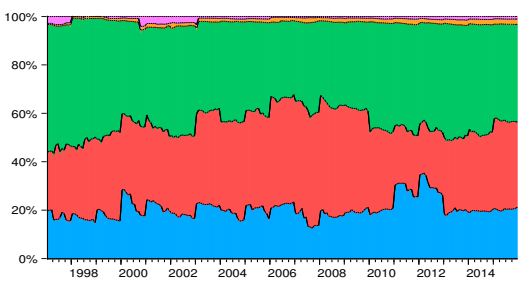


Figure D9: Benchmark
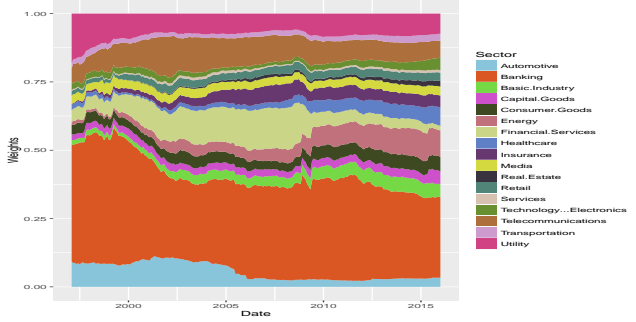

Figure D10: Equally Weighted

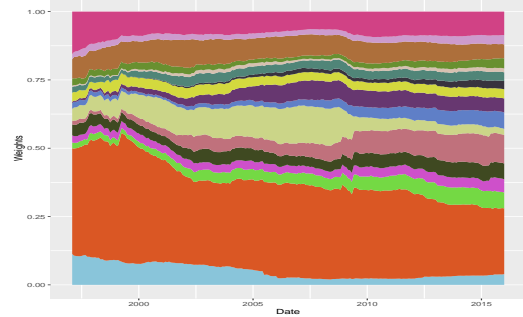

Figure D12: Issuer parity

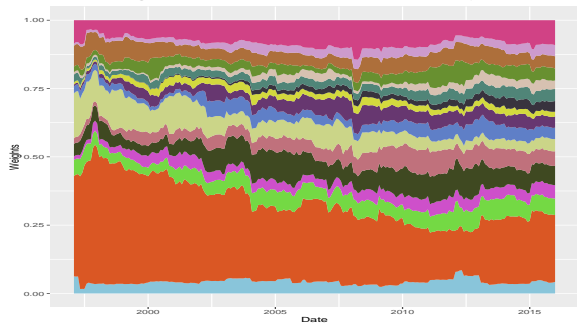

Figure D14: Sector parity

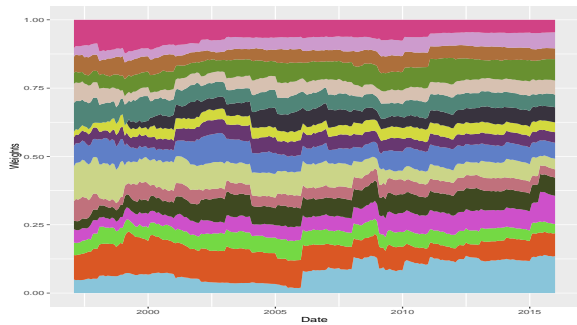

Figure D16: Full parity

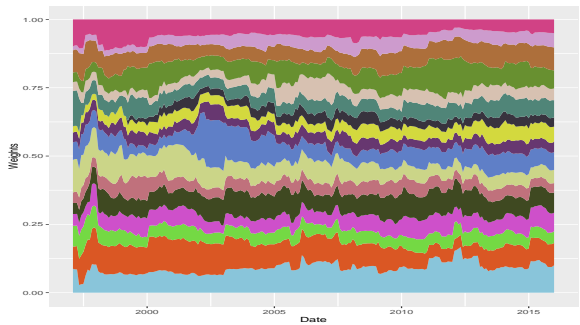




\section{E Principal Components Analysis}

Figure E1: Term structure

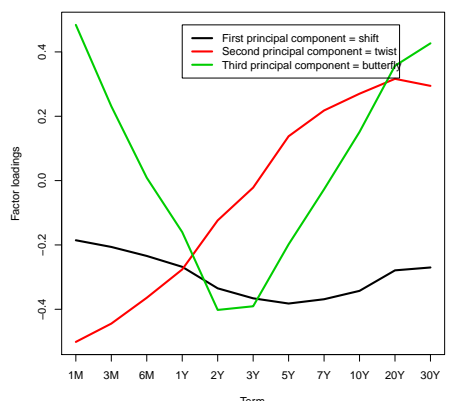

Figure E2: Factors

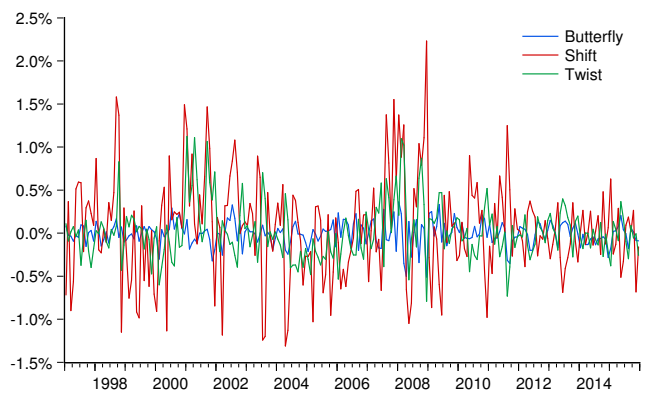

Table E1: Proportion of variance explained

\begin{tabular}{lccc}
\hline & Component 1 & Component 2 & Component 3 \\
\hline Standard deviation & 0.585 & 0.317 & 0.138 \\
Proportion of variance & 0.720 & 0.211 & 0.040 \\
Cumulative proportion & 0.720 & 0.932 & 0.972 \\
\hline
\end{tabular}

Table E2: Factor loadings

\begin{tabular}{cccccccccccc}
\hline & $1 \mathrm{M}$ & $3 \mathrm{M}$ & $6 \mathrm{M}$ & $1 \mathrm{Y}$ & $2 \mathrm{Y}$ & $3 \mathrm{Y}$ & $5 \mathrm{Y}$ & $7 \mathrm{Y}$ & $10 \mathrm{Y}$ & $20 \mathrm{Y}$ & $30 \mathrm{Y}$ \\
\hline Component 1 & -0.19 & -0.21 & -0.23 & -0.27 & -0.33 & -0.37 & -0.38 & -0.37 & -0.34 & -0.28 & -0.27 \\
Component 2 & -0.50 & -0.44 & -0.36 & -0.28 & -0.12 & -0.02 & 0.14 & 0.22 & 0.27 & 0.32 & 0.29 \\
Component 3 & 0.48 & 0.23 & 0.01 & -0.16 & -0.40 & -0.39 & -0.20 & -0.03 & 0.15 & 0.36 & 0.43 \\
\hline
\end{tabular}

